\title{
Safety and efficacy of valproic acid preparations
}

\author{
E. Pasternak ${ }^{\mathrm{a}}$, R. Alyautdin ${ }^{\mathrm{a} *}$, I. Asetskaya ${ }^{\mathrm{b}}$, V. Lepakhin ${ }^{\mathrm{a}}$, B. Romanov and V. Merculov ${ }^{\mathrm{a}}$ \\ ${ }^{a} F e d e r a l$ State Budgetary Institution "Scientific Centre for Expert Evaluation of Medicinal Products", \\ Moscow, Russia \\ ${ }^{\mathrm{b}}$ Federal State Budgetary Institution "Informational-Methodological Centre for Expertise, Accounting \\ and Analysis of Medicinal Products Circulation”, Moscow, Russia
}

*Corresponding author. E-mail: alyautdin@mail.ru

BACKGROUND: Rising of the cost of drug therapy is one of the most notable negative tendencies of modern medicine. The main reasons for this trend are the increased costs for preclinical and clinical phases of drug development. Reproduction of drugs after cessation of patent protection is much less costly. Replacement of the original (reference) drug to generics would greatly reduce the cost of drug therapy. However, the use of generic drugs should provide maintaining quality of medication similar to achieved using the original drug. Thus, the original and generic medicines should be interchangeable and this factor largely determines the fate of the generics. In the Russian Federation the concept of drug interchangeability is entered by the Federal law of Russian Federation № 429-FZ from 22.12.2014. According to this law interchangeable drug is a drug with proven therapeutic equivalence or bioequivalence against the reference drug, having equivalent qualitative and quantitative composition, composition of active ingredients, the composition of excipients, same dosage form and route of administration. Especially the problem of interchangeability is particularly relevant for the drugs with a narrow range of therapeutic action, which include some anticonvulsants [1-3].

OBJECTIVE: In this regard the comparative analysis of indicators efficiency/risk using the data from the Federal database of adverse drug reaction in group of the patients treated with preparations of valproic acid is of interest [4].

METHODS: Assessment of the degree of certainty of causality between the development of adverse reactions and the use of the drugs of valproic acid in our research was assessed with Naranjo scale [5]. This method involves the use of the questionnaire focused on the obtaining concrete answers that are measured quantitatively in points. A certain number of points correspond to a certain degree of reliability.

The category of the degrees of reliability of the relationship "medicine - no" on a scale Naranjo as a result of answers to 10 questions are defined as:

the certain .9 and more points

the probable 5-8 points

the possible $1-4$ points

the doubtful .0 and less points

After determining the degree of certainty of causality, spontaneous reports only having a high degree of reliability reports (definite, probable and possible) were exposed to the further analysis. 
RESULTS: The Federal database of adverse drug reaction contains 753 spontaneous reports on the development of adverse reactions after the use of valproic acid preparations during the study period. Among 753 reports, 216 (29\%) contained information about replacing one drug with another. The analysis of the action of drugs have shown that on the replacement of different drug forms of the original brand, adverse reactions occurred in 23 cases $(14.6 \%)$, but on the replacement of the original drug on generic - in $135(85,4 \%)$ cases. On the basis of clinical picture and assessment of severity of adverse reactions it was found that in $127(77 \%)$ cases adverse reactions were serious. The criteria for seriousness of adverse reaction most often were clinically significant event and hospitalization or its prolongation.

Analysis of the distribution of adverse reactions on replacement of drug preparations showed that 122 (77\%) of 158 spontaneous reports were due to the problems of replacing the original drug to generic.

CONCLUSIONS: Thus, replacement of the original preparation of valproic acid with generics should be considered as an independent risk factor for development of complications of drug therapy. In clinical practice, in case of successful seizure control substitutions of different preparations of valproic acid should be avoided.

Keywords: Antiepileptic drugs, valproic acid, safety, efficacy, interchangeability

\section{Conflict of interest statement: None.}

\section{References}

[1] Andermann F, Duh MS, Gosselin A. Paradis PE Compulsory generic switches of antiepileptic drugs: High switchback rates tobranded compounds compared with other drug classes. Epilepsia. 03/2007; 48(3):464-9. doi: 10.1111/j.15281167.2007.01007.

[2] Besag FMC. Is generic prescribing acceptable in epilepsy? Drug Safety. 2000;23(3):173-82. doi: 10.2165/00002018200023030-00001

[3] Crawford P, Feely M, Guberman A, Kramer G. Are there potential problems with generic substitution of antiepileptic drug? Seizure. 2006;15(3):165-76. doi:10.1016/j.seizure.2005.12.010

[4] Pasternac E, Alyautdin R, Romanov B. Transformation of views on the teratogenic effects of antiepileptic drugs. Safety\&RiskofPharmacotherapy.2014;4:12-17Availablefrom:http://journals.regmed.ru/Content/File.aspx?id=3dc641cc$63 \mathrm{c} 4-45 \mathrm{f} 0-9674-75 \mathrm{f} 87 \mathrm{bf} 35 \mathrm{ba} 6$

[5] Naranjo CA, Busto U, Sellers EM, et al. A method for estimating the probability of adverse drug reactions. Clin Pharmacol Ther. 1981 Aug;30(2):239-45. doi: 10.1038/clpt.1981.154 